\title{
Variabilidade genética entre acessos de amendoim
}

\author{
Wardsson Lustrino Borges ${ }^{(1)}$, Gustavo Ribeiro Xavier ${ }^{(1)}$ e Norma Gouvêa Rumjanek ${ }^{(1)}$
}

\begin{abstract}
(1)Embrapa Agrobiologia, BR 465, Km 07, CEP 23890-000 Seropédica, RJ. E-mail: wardsson@cnpab.embrapa.br, gustavo@cnpab.embrapa.br, norma@cnpab.embrapa.br
\end{abstract}

\begin{abstract}
Resumo - O objetivo deste trabalho foi avaliar a variabilidade genética entre 29 acessos de amendoim (Arachis hypogaea L.), por meio de marcadores moleculares randômicos (DNA polimórfico amplificado ao acaso - RAPD). O ensaio molecular foi realizado com 31 iniciadores, dos quais 12 (39\%) mostraram polimorfismo. Observou-se o total de 145 fragmentos amplificados, dos quais 35 (24\%) foram polimórficos, com média de 4,67 fragmentos por iniciador e 1,13 fragmento polimórfico por iniciador. Pelo dendrograma, observou-se que os acessos foram separados em dois grupos com $89 \%$ de similaridade. Esta distribuição mostra a variabilidade existente entre os acessos das diferentes variedades botânicas, uma vez que acessos da subespécie fastigiata estão presentes nos dois grupos principais, e os acessos da subespécie hypogaea estão distribuídos pelos subgrupos A e B do grupo II do dendograma.
\end{abstract}

Termos para indexação: Arachis hypogaea, diversidade genética, marcadores moleculares, RAPD.

\section{Genetic variability among peanut accessions}

\begin{abstract}
The objective of this study was to evaluate the genetic variability among 29 accessions of peanut (Arachis hypogaea L.) by means of random molecular markers (random amplified polimorphic DNA - RAPD). The molecular assay was performed with 31 primers, of which $12(39 \%)$ revealed polymorphism. It was observed a total of 145 amplified fragments, of which 35 (24\%) were polymorphic, with an average of 4.67 fragments by primer and 1.13 polymorphic fragment by primer. It was observed through the dendrogram that the accessions were separated into two groups with $89 \%$ of similarity. This distribution shows the variability among the accessions of the different botanical varieties, since the accessions of subspecie fastigiata are present in two principal groups, and the accessions of subspecie hypogaea are distributed in subgroups A and B from dendrogram group II.
\end{abstract}

Index terms: Arachis hypogaea, genetic diversity, molecular markers, RAPD.

\section{Introdução}

$\mathrm{O}$ amendoim (Arachis hypogaea L.) pertencente ao gênero Arachis, secção Arachis, é amplamente cultivado em mais de 80 países da América, Ásia e África (Moretzsohn et al., 2004). Considerado como apreciável fonte de matéria graxa, a produção de amendoim alcançou 35,6 milhões de toneladas em vagem e 5,8 milhões de toneladas em óleo, por ano, e está entre as cinco culturas mais importantes em termos de produção de óleo no mundo (Moretzsohn et al., 2005), da qual participa com $10 \%$ da produção de óleo comestível. A China, os EUA e a Índia são os maiores produtores mundiais (He et al., 2003). O Brasil, com uma área plantada de 113,1 mil ha, alcançou, na safra de 2005/ 2006, a produção de 267,7 mil toneladas, com estimativa, para a safra de 2006/2007, de área plantada de 103,5 mil ha e produção de 224,7 mil toneladas (Conab, 2007).

A espécie A. hypogaea é classificada conforme a ausência ou a presença de flores no eixo principal em duas subespécies, hypogaea e fastigiata, respectivamente, divididas em seis variedades botânicas, conforme o hábito de crescimento - subespécie hypogaea: hypogaea e hirsuta; subespécie fastigiata: fastigiata, vulgaris, aequatoriana e peruviana (Krapovickas \& Gregory, 1994). O amendoim também é classificado agronomicamente, conforme caracteres vegetativos e reprodutivos, como pertencente aos grupos Valência (A. hypogaea subsp. fastigiata var. fastigiata), Spanish (A. hypogaea subsp. fastigiata var. vulgaris) e Virgínia (A. hypogaea subsp. hypogaea var. hypogaea) (Godoy et al., 1999). 
Apesar da existência de substancial diversidade entre genótipos de amendoim para várias características morfológicas, fisiológicas e agronômicas, pouca variação tem sido detectada quando se usam proteínas ou marcadores baseados em DNA (Halward et al., 1991; Hopkins et al., 1999; He et al., 2003; Moretzsohn et al., 2004, 2005). Em razão do baixo polimorfismo no DNA, não se tem obtido progresso no mapeamento genético, seleção assistida por marcadores moleculares e estudos evolucionários na cultura do amendoim, em comparação a outras culturas (He et al., 2003).

Marcadores moleculares são úteis nos estudos de detecção de variabilidade genética, melhoramento vegetal e evolução. Entre estes, os marcadores isoenzimáticos permitem o estudo de um número limitado de loci, enquanto os marcadores do tipo RFLP (restriction fragment length polymorphism), AFLP (amplified fragment length polymorphism), e VNTR (variable number of tandem repeats) são caros, laboriosos e geralmente necessitam de marcação radioativa. Os marcadores do tipo RAPD (random amplified polymorphic DNA) (Williams et al., 1990) superam estas limitações, uma vez que muitos loci podem ser estudados simultaneamente e, associados à possibilidade de utilização de vários iniciadores, garantem a análise de uma amostra significativa de todo o genoma (Dias et al., 2003).

Marcadores moleculares RAPD têm sido utilizados para estudos de variabilidade genética (Subramanian et al., 2000; Raina et al., 2001; Xavier et al., 2005) para identificação de espécies (Martin et al., 1997), para monitorar a eventual transferência de material genético de espécies diplóides selvagens para o amendoim cultivado (Garcia et al., 2006), para determinar o grau de associação entre a distância genética entre parentes e a performance dos seus híbridos (Dias et al., 2003), e para construção de mapas genéticos de ligação (Menéndez et al., 1997). A técnica do RAPD pode ser eficaz na redução do número de acessos analisados, uma vez que permite a identificação de acessos contrastantes (Xavier et al., 2005).

$\mathrm{O}$ reconhecimento da variabilidade genética de espécies vegetais pode revelar os maiores contrastes existentes no germoplasma. No caso de leguminosas que se associam com bactérias diazotróficas, capazes de fixar nitrogênio atmosférico, o uso de RAPD assume importância estratégica para a identificação de especificidade entre o macro e microssimbionte, a partir da variabilidade genética vegetal (Xavier et al., 2005, 2006), o que permite a seleção de associações simbióticas mais eficientes e específicas e a aplicação biotecnológica de inoculantes rizobianos, para a otimização da fixação biológica do nitrogênio.

O objetivo deste trabalho foi avaliar a variabilidade genética entre 29 acessos de amendoim, por meio do uso de marcadores moleculares RAPD.

\section{Material e Métodos}

Foram utilizados 29 acessos de amendoim, provenientes do Instituto Agronômico (Campinas, SP), da Embrapa Algodão (Campina Grande, PB) e da Embrapa Recursos Genéticos e Biotecnologia (Brasília, DF) (Tabela 1).

O DNA total foi extraído conforme Ferreira \& Grattapaglia (1998), com algumas modificações. Duas quantidades de tecido foliar do primeiro tretrafólio para

Tabela 1. Origem, variedade botânica, grupo agronômico e hábito de crescimento dos acessos de amendoim (Arachis hypogaea), utilizados no estudo de variabilidade genética por meio de marcador molecular tipo RAPD.

\begin{tabular}{|c|c|c|c|c|}
\hline Acessos & Origem & $\begin{array}{l}\text { Variedade } \\
\text { botânica }\end{array}$ & $\begin{array}{c}\text { Grupo } \\
\text { agronômico }\end{array}$ & $\begin{array}{c}\text { Hábito de } \\
\text { crescimento }\end{array}$ \\
\hline$\overline{76 \mathrm{AM}}$ & África-senegal & vulgaris & Spanish & Ereto \\
\hline 192AM & África & vulgaris & Spanish & Ereto \\
\hline 198AM & África & vulgaris & Spanish & Ereto \\
\hline 214AM & África & vulgaris & Spanish & Ereto \\
\hline 208AM & África & vulgaris & Spanish & Ereto \\
\hline 193AM & África & vulgaris & Spanish & Ereto \\
\hline 206AM & África & vulgaris & Spanish & Ereto \\
\hline 218AM & África & vulgaris & Spanish & Ereto \\
\hline 202AM & África & vulgaris & Spanish & Ereto \\
\hline 174AM & Argentina & hypogaea & Virgínia & Rasteiro \\
\hline Sapucaia Bege & Brasil & fastigiata & Valência & Ereto \\
\hline Sapucaia Vermelha & Brasil & fastigiata & Valência & Ereto \\
\hline Serrinha & Brasil & fastigiata & Valência & Ereto \\
\hline 158AM & Brasil & fastigiata & Valência & Ereto \\
\hline 178AM & Brasil & fastigiata & Valência & Ereto \\
\hline 185AM & Brasil & fastigiata & Valência & Ereto \\
\hline 184AM & Brasil & fastigiata & Valência & Ereto \\
\hline 180AM & Brasil & vulgaris & Spanish & Ereto \\
\hline IAC 886 Runner & Brasil & hypogaea & Virgínia & Rasteiro \\
\hline IAC Tatu ST & Brasil & fastigiata & Valência & Ereto \\
\hline IAC 8112 & Brasil & vulgaris & Spanish & Ereto \\
\hline IAC Caiapó & Brasil & hypogaea & Virgínia & Rasteiro \\
\hline V12549 & Brasil & $\mathrm{nd}^{(1)}$ & $\mathrm{nc}^{(2)}$ & nc \\
\hline V12548 & Brasil & hypogaea & $\mathrm{nc}$ & nc \\
\hline CV Tatuí & Brasil & vulgaris & Spanish & Ereto \\
\hline CV Tatu & Brasil & fastigiata & Valência & Ereto \\
\hline Mf 1538 & Equador & hirsuta & nc & nc \\
\hline Mf 1560 & Equador & peruviana & $\mathrm{nc}$ & $\mathrm{nc}$ \\
\hline Md 1678 & Equador & aequatoriana & nc & nc \\
\hline
\end{tabular}

(1)Variedade botânica não determinada. ${ }^{(2)}$ Acesso não cultivado. 
a extração foram testadas: um e três discos de tecido foliar com diâmetro de $1 \mathrm{~cm}$, que correspondem à cerca de 10 e $30 \mathrm{mg}$, respectivamente (Xavier et al., 2005). $\mathrm{O}$ disco de tecido foliar foi macerado em nitrogênio líquido até o estado de pó fino, ressuspendido em tampão de extração (CTAB 2\%; 20 mM EDTA; 100 mM Tris$\mathrm{HCl} \mathrm{pH} 8 ; 1 \%$ mercaptoetanol) e incubado a $65^{\circ} \mathrm{C}$ por 60 min. Após a incubação, adicionaram-se $600 \mu \mathrm{L}$ de clorofórmio-álcool isoamílico (24:1), e as amostras foram centrifugadas a $16.100 \mathrm{~g}$ por $10 \mathrm{~min}$. O sobrenadante foi transferido para um microtubo novo, e o DNA foi precipitado, tendo-se adicionado $2 / 3$ do volume de isopropanol gelado e incubado as amostras a $4^{\circ} \mathrm{C}$ por $60 \mathrm{~min}$. Após esse período, as amostras foram centrifugadas a $16.100 \mathrm{~g}$ por $8 \mathrm{~min}$, o sobrenadante foi descartado, e o precipitado foi lavado duas vezes com etanol $70 \%$ (v/v) por $10 \mathrm{~min}$, e uma vez com etanol absoluto por 5 min. Em seguida, o precipitado foi secado em centrífuga a vácuo, a $35^{\circ} \mathrm{C}$ por aproximadamente $15 \mathrm{~min}$, e ressuspendido em $25 \mu \mathrm{L}$ de TE (Tris- $\mathrm{HCl}$ $10 \mathrm{mM} \mathrm{pH}$ 8; EDTA $1 \mathrm{mM}$ ). A quantidade de DNA foi determinada, tendo-se mensurado a absorbância a $260 \mathrm{~nm}$.

A reação de PCR-RAPD foi otimizada, tendo-se testado oito diferentes misturas, resultantes da combinação entre duas massas do DNA molde (25 e $37,5 \mathrm{ng})$, duas concentrações de iniciadores $(0,3 \mathrm{e}$ $0,5 \mu \mathrm{M})$ e duas concentrações de cloreto de magnésio (1,5 e $2 \mathrm{mM}$ ), a fim de se obter uma condição capaz de produzir um perfil com bandas intensas e reprodutíveis. A reação foi realizada com volume total de $25 \mu \mathrm{L}$, composto, ainda, por $200 \mu \mathrm{M}$ de cada dNTP, $0,5 \mu \mathrm{g} \mu \mathrm{L}^{-1}$ de BSA (soro de albumina bovina), tampão 1x (20 mM Tris- $\mathrm{HCl} \mathrm{pH} 8 ; 50 \mathrm{mM} \mathrm{KCl}$ ) e $1 \mathrm{U}$ Taq polimerase (Invitrogen Life Technologies). A otimização das condições de amplificação compreendeu, também, a otimização na temperatura de anelamento, que variou de 34,9 a $55,7^{\circ} \mathrm{C}$. Nesta faixa, foram testadas 12 temperaturas diferentes. O esquema de temperatura para a reação de amplificação foi o seguinte: $94^{\circ} \mathrm{C}$ por 1 min, para desnaturação inicial, seguido de 34 ciclos de $92^{\circ} \mathrm{C}$ por $1 \mathrm{~min}$, gradiente de 34,9 a $55,7^{\circ} \mathrm{C}$ na etapa de anelamento por $1 \mathrm{~min}, \mathrm{e} 72^{\circ} \mathrm{C}$ por $2 \mathrm{~min}$, com uma etapa final de extensão por $5 \mathrm{~min}$ a $72^{\circ} \mathrm{C}$. Utilizou-se o termociclador modelo Mastercycler Gradient (Eppendorf).

Procedeu-se à seleção dos iniciadores decâmeros e da temperatura de anelamento para a análise de RAPD, e se realizou a reação de PCR-RAPD com 40 iniciadores dos kits A e B (Operon Technologies), na condição de amplificação anteriormente definida, e o gradiente de 34,9 a $55,7^{\circ} \mathrm{C}$ na etapa de anelamento. Para o ensaio RAPD com os 29 acessos de amendoim, além dos iniciadores selecionados a partir dos kits A e B, foram utilizados 10 iniciadores decâmeros (University of Bristish Columbia - UBC23, UBC25, UBC302, UBC336, UBC346, UBC355, UBC391, UBC400, UBC776, UBC788), selecionados por He \& Prakash (1997). A condição da reação de amplificação com estes 10 iniciadores foram as descritas por He \& Prakash (1997) para caracterizar germoplasma de amendoim.

Os fragmentos amplificados foram submetidos à separação eletroforética em gel de agarose $(1,4 \% \mathrm{p} / \mathrm{v})$, com voltagem constante de $7 \mathrm{~V} \mathrm{~cm}^{-1}$, por $105 \mathrm{~min}$. Os géis foram corados com brometo de etídio e fotografados sob luz UV. Os perfis de bandas, obtidos com os iniciadores capazes de gerar polimorfismo, foram convertidos em matriz binária de presença e ausência de bandas (0 para ausência e 1 para presença). A partir dessa matriz foi construído o dendrograma, tendo-se utilizado o algoritimo UPGMA e o índice de similaridade de Dice $\left(S_{i j}=2 \mathrm{a} / \mathrm{a}+\mathrm{b}+\mathrm{c}\right)$, que não considera as duplas ausências no cálculo da similaridade entre os acessos, no programa NTSys2.1 (Rohlf, 1994).

\section{Resultados e Discussão}

A extração de DNA foi realizada com um disco de tecido foliar jovem para todas as amostras, quantidade semelhante obtida por Xavier et al. (2005) e, de acordo com os dados de quantificação, foi observada a variação de 5 a $23,75 \mu \mathrm{g}$ de DNA extraído. As concentrações de DNA, de iniciador e de $\mathrm{MgCl}_{2}$ não produziram perfis de bandas diferentes, tendo-se observado apenas pequenas variações na intensidade das bandas e, em temperaturas superiores a $51^{\circ} \mathrm{C}$, não foi observada amplificação. As condições selecionadas após a etapa de otimização foram de $25 \mathrm{ng}$ de DNA, 0,5 $\mu \mathrm{M}$ de iniciador e $1,5 \mathrm{mM}$ de $\mathrm{MgCl}_{2}$. A temperatura selecionada foi de $38^{\circ} \mathrm{C}$, a mais elevada em que houve amplificação comum aos iniciadores.

Dos 40 iniciadores testados da linha Operon, 21 produziram amplificação (OPA2, OPA3, OPA4, OPA5, OPA8, OPA13, OPA14, OPA15, OPA16, OPA17, OPA18, OPB5, OPB6, OPB7, OPB10, OPB11, OPB12, OPB13, OPB15, OPB17, OPB18). O ensaio RAPD foi realizado com 31 iniciadores: 21 da Operon Technologies e 10 da UBC. Do total de 31 iniciadores, 12 (39\%) revelaram polimorfismo em amendoim, enquanto 19 (61\%) deles não 
revelaram polimorfismo. Entre os 21 iniciadores testados, $33 \%$ da Operon foram polimórficos, enquanto $50 \%$ dos 10 iniciadores da UBC foram polimórficos.

Em outro estudo, 70 acessos de amendoim, com diferentes características como tolerância à seca, período de maturação, dormência de sementes, massa de 100 sementes, conteúdo de óleo, entre outras, foram analisados com 48 iniciadores randômicos, e apenas sete $(15 \%)$ iniciadores revelaram polimorfismo (Subramanian et al., 2000). Com uso de outras técnicas para revelar polimorfismo em amendoim, He \& Prakash (1997, 2001) observaram polimorfismo em: 17 (3\%) dos 559 iniciadores DAF (DNA amplification fingerprint); 28 (43\%) dos 64 pares de iniciadores AFLP testados; e 15 dos 28 pares de iniciadores AFLP testados. Para estes autores, o porcentual de iniciadores que revelou polimorfismo foi baixo e isso apóia a hipótese de que A. hypogaea pode ter surgido recentemente, como resultado de um evento simples de poliploidização (Halward et al., 1991), e ressaltam ainda que, em uma espécie evolucionariamente recente, é provável que substituições simples de nucleotídeos expliquem melhor a variabilidade genética, do que diferenças robustas em poucos loci (He \& Prakash, 1997).

Os 21 iniciadores dos kits Ae B da Operon Technologies testados amplificaram 83 fragmentos, dos quais sete revelaram 15 fragmentos polimórficos; e os 10 iniciadores da UBC testados amplificaram 62 fragmentos, dos quais cinco amplificaram 20 fragmentos polimórficos. Quando se analisaram todos os 31 iniciadores, observou-se um total de 145 fragmentos amplificados, em que 35 (24\%) foram polimórficos (Tabela 2). Foi observada a média de

Tabela 2. Número de fragmentos e número de perfis de bandas, obtidos com 12 iniciadores RAPD.

\begin{tabular}{lccc}
\hline Iniciador & $\begin{array}{c}\mathrm{N}^{\mathbf{0}} \text { de fragmentos } \\
\text { amplificados }\end{array}$ & $\begin{array}{c}\mathrm{N}^{\mathbf{0}} \text { de fragmentos } \\
\text { polimórficos }\end{array}$ & $\begin{array}{r}\mathrm{N}^{\mathbf{0}} \text { de perfis } \\
\text { de bandas }\end{array}$ \\
\hline OPA4 & 9 & 4 & 3 \\
OPA5 & 3 & 2 & 3 \\
OPA8 & 4 & 1 & 2 \\
OPA14 & 5 & 3 & 3 \\
OPA16 & 2 & 1 & 2 \\
OPB10 & 3 & 3 & 2 \\
OPB18 & 9 & 1 & 2 \\
UBC23 & 7 & 5 & 2 \\
UBC25 & 12 & 4 & 2 \\
UBC302 & 10 & 7 & 3 \\
UBC346 & 5 & 2 & 3 \\
UBC788 & 4 & 2 & 3 \\
\hline Total & $145(73)$ & 35 & - \\
\hline
\end{tabular}

4,67 fragmentos por iniciador e 1,13 fragmento polimórfico por iniciador. Os tamanhos dos fragmentos amplificados variaram, aproximadamente, entre $300 \mathrm{pb}$ com o iniciador UBC 346 e $2.300 \mathrm{pb}$ com o UBC302. Raina et al. (2001) observaram que entre 220 fragmentos amplificados por 21 iniciadores randômicos, 94 foram polimórficos $(42,7 \%)$; seis $(6,4 \%)$ de um total de 94 fragmentos AFLP, foram polimórficos entre os acessos de $A$. hypogaea (Gimenes et al., 2002); entre 3.241 fragmentos AFLP, 90 foram polimórficos entre acessos de $A$. hypogaea (Herselman, 2003). Comparando-se esses resultados, gerados por dois tipos de marcadores dominantes, pode-se observar que os marcadores RAPD foram mais informativos, na identificação de polimorfismo.

Entre os 70 acessos de amendoim analisados por Subramanian et al. (2000), para os dois iniciadores que mais diferenciaram os acessos foi observada a variação em 12 e 13 acessos, respectivamente, o que indica que a variabilidade identificada por cada iniciador é baixa, e que se torna necessária a utilização de um elevado número de iniciadores, para a identificação de polimorfismo entre os acessos. No presente trabalho, os iniciadores da UBC amplificaram um número médio de fragmentos superior aos iniciadores da Operon, tanto entre os que revelaram polimorfismo, quanto entre os que produziram perfis monomórficos (Tabela 3 ).

Pelo agrupamento obtido com o índice Dice (Figura 1), observou-se a formação de dois grupos principais, com nível de similaridade de $89 \%$, o primeiro (I) composto por três acessos (IAC Tatu ST, 214AM e 198AM), e o segundo (II) grupo, subdividido em dois subgrupos (A e B), com 26 acessos (A: 76AM, Mf 1538, 158AM, 206AM, 218AM, Sapucaia Vermelha, CV Tatu, 202AM, CV Tatuí, 180AM, Md 1678, Sapucaia Bege, 174AM, 192AM, Serrinha, 184AM, 193AM, 178AM, 185AM, IAC 886 Runner, 208AM e IAC 8112; B: V12549, V12548, Mf 1560 e IAC Caiapó).

Tabela 3. Número médio de fragmentos amplificados e erropadrão da média dos diferentes iniciadores testados, polimórficos e monomórficos.

\begin{tabular}{lccccc}
\hline \multirow{2}{*}{ Iniciador } & \multicolumn{2}{c}{ Com polimorfismo } & & \multicolumn{2}{c}{ Sem polimorfismo } \\
\cline { 2 - 3 } \cline { 5 - 6 } & Média & Erro-padrão & & Média & Erro-padrão \\
\hline Operon & 5,00 & 1,09 & & 3,43 & 0,55 \\
UBC & 7,60 & 1,50 & & 4,80 & 1,59 \\
\hline
\end{tabular}


No grupo I do dendrograma, estão $11 \%$ dos acessos da variedade fastigiata e $17 \%$ dos acessos da variedade vulgaris. No subgrupo A do grupo II, estão $50 \%$ dos acessos da variedade hypogaea, 100\% dos acessos da variedade hirsuta, ambas da subespécie hypogaea; $100 \%$ dos acessos da variedade aequatoriana, 89\% dos acessos da variedade fastigiata, $83 \%$ dos acessos da variedade vulgaris. No subgrupo B, estão $50 \%$ dos acessos da variedade botânica hypogaea e 100\% dos acessos da variedade peruviana. Esta distribuição mostra a variabilidade existente entre os acessos das diferentes variedades botânicas, uma vez que acessos da subespécie fastigiata estão presentes nos dois grupos principais, e os acessos da subespécie hypogaea estão distribuídos nos subgrupos A e B, do grupo II do dendrograma.

He \& Prakash (2001) observaram a formação de dois grupos principais entre acessos de diferentes variedades de amendoim, e não foi observada correspondência com a classificação morfológica. Os autores citam que os dados de polimorfismo de DNA não estão de acordo com a classificação de Arachis hypogaea quanto às duas subespécies. Em ensaio com marcadores RAPD, os cinco grupos gerados pela análise de agrupamento apresentaram acessos que não puderam ser associados aos seus países de origem, às subespécies, às características das sementes e vagens, nem ao conhecimento do pedigree (Dwivedi et al., 2001). Raina et al. (2001) analisaram 13 acessos de amendoim representantes de cinco variedades botânicas e observaram um agrupamento coerente com a classificação morfológica.

Os acessos brasileiros se distribuíram por todos os grupos do dendrograma e mostraram variabilidade maior, quando comparados aos acessos africanos, que não possuem nenhum representante no subgrupo B do grupo II. Dos três acessos do Equador, dois ficaram no subgrupo A e um no subgrupo B do grupo II. Herselman

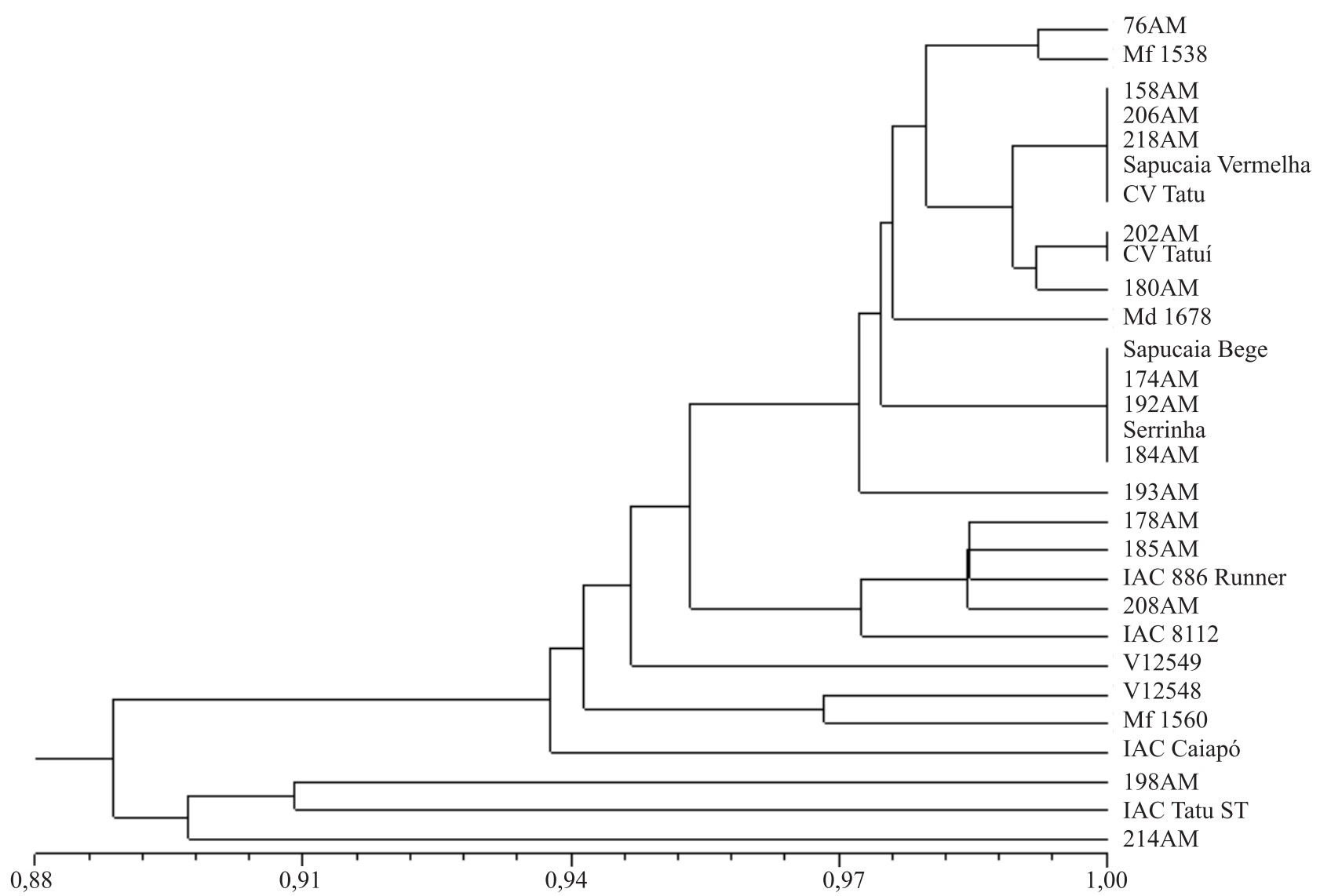

Figura 1. Dendrograma dos grupos formados e a similaridade genética entre os 29 acessos de amendoim, construído com os marcadores RAPD obtidos com 12 iniciadores. 
(2003) aponta que: o primeiro acesso introduzido, a partir do qual se estabeleceu a cultivar Natal Common na África do Sul, era do tipo Spanish; os acessos introduzidos, do grupo Valência, não se adaptaram agronomicamente; os acessos atualmente cultivados originam-se de cruzamentos que envolvem a cultivar Natal Common.

Entre os 26 acessos no grupo II, 12 distribuídos em três sub-grupos geneticamente distintos apresentaram, dentro de cada grupo, $100 \%$ de similaridade, o que mostra que embora um elevado número de iniciadores tenha sido utilizado, esses acessos não puderam ser diferenciados. Os dados do presente trabalho estão de acordo com os apresentados na literatura, que mostram polimorfismo baixo para a espécie Arachis hypogaea, mesmo quando se utilizam marcadores considerados mais informativos (Hopkins et al., 1999; He et al., 2003, 2005; Ferguson et al., 2004; Moretzsohn et al., 2004, 2005).

O baixo polimorfismo no amendoim tem sido atribuído a causas como barreiras ao fluxo gênico das espécies diplóides selvagens para o amendoim, como conseqüência do evento da poliploidização, recente poliploidização de um ou poucos indivíduos de cada espécie diplóide parental, autopolinização e o uso de poucas linhas e de pouco germoplasma exótico em programas de melhoramento (Moretzsohn et al., 2004, 2005).

Além dessas causas, o número e a base genética de acessos utilizados, o número de enzimas e sondas utilizadas, os tipos de clones e a habilidade destes em revelar polimorfismo, o número de iniciadores utilizados, o pequeno comprimento dos cromossomos, loci multialélicos, a presença de muitas sequiências repetitivas e redundantes, e o confinamento das sequiências funcionais em regiões pequenas, também podem ter contribuído para o baixo polimorfismo (Singh et al., 1998). Para superar essas limitações, alguns autores aumentaram o número de iniciadores utilizados (Dwivedi et al., 2001; Raina et al., 2001), analisaram acessos de diferentes variedades botânicas (Subramanian et al., 2000; Raina et al., 2001) e, mais recentemente, iniciadores microssatélites têm sido desenvolvidos e utilizados em estudos de diversidade genética, em várias espécies do gênero Arachis (Hopkins et al., 1999; He et al., 2003, 2005; Ferguson et al., 2004; Moretzsohn et al., 2004, 2005; Palmieri et al., 2005; Bravo et al., 2006; Hoshino et al., 2006).

\section{Conclusões}

1. Há variabilidade entre os acessos das diferentes variedades botânicas da espécie Arachis hypogaea.

2. O agrupamento por RAPD não está relacionado à classificação morfológica das variedades botânicas da espécie Arachis hypogaea.

3. Observa-se, pelo dendrograma, a separação de dois grupos principais com $89 \%$ de similaridade.

4. Dos materiais analisados, 12 acessos apresentam $100 \%$ de similaridade e estão distribuídos em três subgrupos, o que não carateriza contraste entre esses acessos.

\section{Agradecimentos}

Ao Conselho Nacional de Desenvolvimento Científico e Tecnológico, por bolsa concedida; ao Sr. Ignácio José de Godoy, do Instituto Agronômico, ao Sr. José Francisco Montenegro Valls, da Embrapa Recursos Genéticos e Biotecnologia, e à Sra. Tais Moraes Falleiro Suassuna, da Embrapa Algodão, pelo fornecimento dos acessos utilizados.

\section{Referências}

BRAVO, J.P.; HOSHINO, A.A.; ANGELICI, C.M.L.C.D.; LOPES, C.R.; GIMENES, M.A. Transferability and use of microsatellite markers for the genetic analysis of the germplasm of some Arachis section species of the genus Arachis. Genetics and Molecular Biology, v.29, p.516-524, 2006.

CONAB. Companhia Nacional de Abastecimento. Brasília: Conab. Disponível em: http://www.conab.gov.br/. Acesso em: 17 jul. 2007.

DIAS, L.A.S.; MARITA, J.; CRUZ, C.D.; BARROS, E.G.; SALOMÃO, T.M.F. Genetic distance and its association with heterosis in cacao. Brazilian Archives of Biology and Technology, v.46, p339-348, 2003.

DWIVEDI, S.L.; GURTU, S.; CHANDRA, S.; YUEJIN, W.; NIGAM, S.N. Assessment of genetic diversity among selected groundnut germplasm: 1- RAPD analysis. Plant Breeding, v.120, p.345-349, 2001.

FERGUSON, M.E.; BUROW, M.D.; SCHULZE, S.R.; BRAMEL, P.J.; PATERSON, A.H.; KRESOVICH, S.; MITCHELL, S. Microsatellite identification and characterization in peanut (A. hypogaea L.). Theoretical and Applied Genetics, v.108, p.1064-1070, 2004.

FERREIRA, M.E.; GRATTAPAGLIA, D. Introdução ao uso de marcadores moleculares em análise genética. 3.ed. Brasília: Embrapa-Cenargen, 1998. 220p. (Embrapa-Cenargen. Documentos, 20). 
GARCIA, G.M.; TALLURY, S.P.; STALKER, H.T.; KOCHERT, G. Molecular analysis of Arachis interspecific hybrids. Theoretical and Applied Genetics, v.112, p.1342-1348, 2006.

GIMENES, M.A.; LOPES, C.R.; VALLS, J.F.M. Genetic relationships among Arachis species based on AFLP. Genetics and Molecular Biology, v.25, p.349-353, 2002.

GODOY, I.J.; MORAES, S.A.; ZANOTTO, M.D.; SANTOS, R.C. Melhoramento do amendoim. In. BOREN, A. (Ed.). Melhoramento de espécies cultivadas. Viçosa: Editora UFV, 1999. p.51-94.

HALWARD, T.M.; STALKER, H.T.; LARUE, E.A.; KOCHERT, G. Genetic variation detectable with molecular markers among unadapted germplasm resources of cultivated peanut and related wild species. Genome, v.34, p.1013-1020, 1991.

HE, G.; MENG, R.; GAO, H.; GUO, B.; GAO, G.; NEWMAN, M.; PITTMAN, R.N.; PRAKASH, C.S. Simple sequence repeat markers for botanical varieties of cultivated peanut (Arachis hypogaea L.) Euphytica, v.142, p.131-136, 2005.

HE, G.; MENG, R.; NEWMAN, M.; GAO, G.; PITTMAN, R.N.; PRAKASH, C.S. Microsatellites as DNA markers in cultivated peanut (Arachis hypogaea L.). BMC Plant Biology, v.3, 2003. Disponível em: http://www.biomedcentral.com/1471-2229/3/3. Acesso em: 10 jul. 2007.

HE, G.; PRAKASH, C.S. Evaluation of genetic relationship among botanical varieties of cultivated peanut (Arachis hypogaea L.) using AFLP markers. Genetic Resources and Crop Evolution, v.48, p.347-352, 2001.

HE, G.; PRAKASH, C.S. Identification of polymorphic DNA markers in cultivated peanut (Arachis hypogaea L.). Euphytica, v.97, p.143-149, 1997.

HERSELMAN, L. Genetic variation among Southern African cultivated peanut (Arachis hypogaea L.) genotypes as revealed by AFLP analysis. Euphytica, v.133, p.319-327, 2003.

HOPKINS, M.S.; CASA, A.M.; WANG, T.; MITCHELL, S.E.; DEAN, R.E.; KOCHERT, G.D.; KRESOVICH, S. Discovery and characterization of polymorphic simple sequence repeats (SSRs) in peanut. Crop Science, v.39, p.1243-1247, 1999.

HOSHINO, A.A.; BRAVO, J.P.; ANGELICI, C.M.L.C.D.; BARBOSA, A.V.G.; LOPES, C.R.; GIMENES, M.A. Heterologous microsatellite primer pairs informative for the whole genus Arachis. Genetics and Molecular Biology, v.29, p.665-675, 2006.

KRAPOVICKAS, A.; GREGORY, W.C. Taxonomía del género Arachis (Legunimosae). Bonplandia, v.8, p.1-186. 1994.

MARTIN, C.; JULIANO, A.; NEWBURY, H.J.; LU, B.R.; JACKSON, M.T.; FORD-LLOYD, B.V. The use of RAPD markers to facilitate the identification of Oryza species within a germplasm collection. Genetic Resources and Crop Evolution, v.44, p.175-183, 1997.
MENÉNDEZ, C.M.; HALL, A.E.; GEPTS, P. A genetic linkage map of cowpea (Vigna unguiculata) developed from a cross between two inbred, domesticated lines. Theoretical and Applied Genetics, v.95, p.1210-1217, 1997.

MORETZSOHN, M.C.; HOPKINS, M.S.; MITCHELL, S.E.; KRESOVICH, S.; VALLS, J.F.M.; FERREIRA, M.E. Genetic diversity of peanut (Arachis hypogaea L.) and its wild relatives based on the analysis of hypervariable regions of the genome. BMC Plant Biology, v.4, 2004. Disponível em: http:// www.biomedcentral.com/1471-2229/4/11. Acesso em: 10 jul. 2007.

MORETZSOHN, M.C.; LEOI, L.; PROITE, K.; GUIMARÃES, P.M.; LEAL-BERTIOLI, S.C.M.; GIMENES, M.A.; MARTINS, W.S.; VALLS, J.F.M.; GRATTAPAGLIA, D.; BERTIOLI, D.J. A microsatellite-based, gene-rich linkage map for the AA genome of Arachis (Fabaceae). Theoretical and Applied Genetics, v.111, p.1060-1071, 2005.

PALMIERI, D.A.; BECHARA, M.D.; CURI, R.A.; GIMENES, M.A.; LOPES, C.R. Novel polymorphic microsatellite markers in section Caulorrhizae (Arachis, Fabaceae). Molecular Ecology Notes, v.5, p.77-79, 2005.

RAINA, S.N.; RANI, V.; KOJIMA, T.; OGIHARA, Y.; SINGH, K.P.; DEVARUMANTH, R.M. RAPD and ISSR fingerprints as useful genetic markers for analysis of genetic diversity, varietal identification, and phylogenetic relationships in peanut (Arachis hypogaea) cultivars and wild species. Genome, v.44, p.763-772, 2001.

ROHLF, F.J. NTSYS-pc: numerical taxonomy and multivariate analysis system, version 1.80. New York: Exeter Software, 1994.

SINGH, A.K.; SMARTT, J.; SIMPSON, C.E.; RAINA, S.N. Genetic variation vis-à-vis molecular polymorphism in groundnut, Arachis hypogaea L. Genetics Resources and Crop Evolution, v.45, p.119-126, 1998.

SUBRAMANIAN, V.; GURTU, S.; RAO, R.C.N.; NIGAM, S.N. Identification of DNA polymorphism in cultivated groundnut using random amplified polymorphic DNA (RAPD) assay. Genome, v.43, p.656-660, 2000.

WILLIAMS, J.G.; KUBELIK, A.R.; LIVAK, K.J.; RAFALSKI, L.A.; TINGEY, S.V. DNA polymorphism amplified by arbitrary primers are useful as genetic markers. Nucleic Acids Research, v.18, p.6531-6535, 1990.

XAVIER, G.R.; MARTINS, L.M.V.; RIBEIRO, J.R.A.; RUMJANEK, N.G. Especificidade simbiótica entre rizóbios e acessos de feijão-caupi de diferentes nacionalidades. Caatinga, v.19, p.25-33, 2006.

XAVIER, G.R.; MARTINS, L.M.V.; RUMJANEK, N.G.; FREIRE FILHO, F.R. Variabilidade genética em acessos de caupi analisada por meio de marcadores RAPD. Pesquisa Agropecuária Brasileira, v.40, p.353-359, 2005. 